\title{
Erratum to: The potential effectiveness of the nutrition improvement program on infant and young child feeding and nutritional status in the Northwest and Southwest regions of Cameroon, Central Africa
}

Kate Reinsma ${ }^{1 *}$, Godlove Nkuoh ${ }^{1}$ and Emmanuel Nshom²

\section{Erratum}

Following the publication of this article [1] it was brought to our attention that there is a recurring error in the 'Results' section of the 'Abstract' and the 'Stunting' section of the 'Results'.

The sentence: "...children were five times (OR: 5.5 ; CI: $3.37,9.02 ; \beta=1.71$ ) more likely to be stunted at non-NIP sites compared to non-NIP sites" should instead read: "... children were five times more likely to be stunted at non-NIP sites compared to NIP sites".

\footnotetext{
Author details

${ }^{1}$ Nutrition Improvement Program, Cameroon Baptist Convention Health Services, P.O Box 1Nkwen, Bamenda, Cameroon. ${ }^{2}$ AIDS Care and Prevention Program, Cameroon Baptist Convention Health Services, Bamenda, Cameroon.
}

Received: 22 February 2017 Accepted: 22 February 2017

Published online: 24 February 2017

\section{Reference}

1. Reinsma K. et al.: The potential effectiveness of the nutrition improvement program on infant and young child feeding and nutritional status in the Northwest and Southwest regions of Cameroon, Central Africa. BMC Health Services Research (2016) 16:654. DOI 10.1186/s12913-016-1899-z

\footnotetext{
* Correspondence: kate.reinsma@gmail.com

${ }^{1}$ Nutrition Improvement Program, Cameroon Baptist Convention Health

Services, P.O Box 1Nkwen, Bamenda, Cameroon
} 